RESEARCH REPORT

\title{
COMPARATIVE ANALYSIS BETWEEN MOBILIZATION WITH MOVEMENT (MWM) AND MANIPULATION IN THE MANAGEMENT OF LATERAL EPICONDYLITIS
}

\begin{abstract}
OBJECTIVES

To compare the effect of Mobilization with Movement (MWM) and Manipulation in the management of lateral epicondylitis with regard to ache, grip power and functional activities.

\section{METHODOLOGY}

20 patients presented with lateral epicondylitis (Tennis elbow) to OPD in Ziauddin Hospital (Clifton, North and Kemari campuses). They were enrolled for the purpose of research study after written informed consent. Subjects were erratically assigned into 2 groups, i.e. group A for MWM and group B for manipulation. All patients were examined before and after the treatment and then findings were evaluated. Pain was sedated by Visual analogue scale (VAS), grip strength was measured by hand-held dynamometer and functional activities' outcomes were measured by forearm analysis questionnaire survey for lateral epicondylitis, by H B Leung et al 2004.

RESULT

A total of 20 patients were randomly selected and divided into two groups i.e. Group-A \& Group-B. The result shows for Group A: The mean of pain score on VAS before treatment was $4.70 \pm 1.418$ while after treatment was $0.10 \pm 0.316$ with $P$ value $(0.05)$ and the mean of grip strength score before treatment was $13.40 \pm 7.442$ while after treatment was $22.60 \pm 8.501$. For Group B: The mean of pain score on VAS before treatment was $5.20 \pm 0.632$ while after treatment was $0.5 \pm 0.527$ with $P$ value $(0.05)$ and the mean of grip strength before treatment was $26.20 \pm 21.028$ and after treatment was $32.00 \pm 24.33$.
\end{abstract}

\section{CONCLUSION}

This study shows evidence to support the effectiveness of both approaches (MWM + Manipulation) for relieving ache, strengthening and functionality along with tennis elbow.

\section{KEYWORDS}

Lateral epicondylitis, Manipulation, Mobilization with movement (MWM), dynamometer, visual analog scale, and analysis.

\section{Fareeda Shaheen}

Consultant Physiotherapist

Department of Physiotherapy

Sindh Government Hospital

Saudabad

Fareeda.shah08@gmail.com

\section{Nazish Rafique}

Senior Lecturer

Ziauddin College of Physical

Therapy

Ziauddin University

nazish2312@gmail.com

\section{Aqsa Izhar Ahmed}

DPT, Student

Ziauddin College of Physical

Therapy

Ziauddin University

Perkash Lal

DPT, Student

Ziauddin College of Physical

Therapy

Ziauddin University

[Shaheen F, Rafique N, Ahmed Al \& Lal P. Comparative analysis between mobilization with movement (MWM) and manipulation in the management of lateral epicondylitis. Pak. j. rehabil. 2016;5(1):45-51] 


\section{INTRODUCTION}

Lateral epicondylitis or Tennis elbow is an affliction and menacing onset of elbow ache during wrist extension, supination and pronation. The pain is aggravated by simply gripping in the hand, like as holding objects, shaking hands, and working out with pot. Morris (1882) has initially mentioned this problem and he called it as lawn tennis arm ${ }^{1-3}$.

Tennis elbow impacts $1-3 \%$ on human population; simply $5 \%$ coming from all patients are witnessed to be recreational tennis players. It mostly happens within the fourth as well as fifth generations. Men and women prevalence is reported identically $75 \%$, of which affected individuals are symptomatic within their main $\operatorname{arms}^{4-6}$. Research directed by Verhaar ${ }^{7}$ disclosed that regarding age, between 40 to 60 years of ages there is $10 \%$ of women and $3 \%$ of men who get affected ${ }^{8}$.

The muscles which are quite frequently implicated scientifically and surgically are extensor carpi radialis brevis, extensor carpi radialis longus, and extensor carpi ulnaris, along with extensor digitorum communis. The potential grounds for the continual participation of the extensor carpi radialis brevis is that it is situated more laterally on the lateral epicondyle acquiring origin on the radial collateral ligament. The extensor carpi radialis brevis is closely attached on the joint capsule, which continues simply by radial collateral ligament and due to this vicinity adhesions are extra likely3.

\begin{tabular}{|l|l|}
\hline \multicolumn{2}{|l|}{ Stages of lateral epicondylitis } \\
\hline Stage 1 & $\begin{array}{l}\text { Exhibits inflammation which } \\
\text { can be reversible. }\end{array}$ \\
\hline Stage 2 & $\begin{array}{l}\text { Irreversible degenerative } \\
\text { changes on origin of } \\
\text { extensor carpi radialisbrevis } \\
\text { muscle. }\end{array}$ \\
\hline Stage 3 & $\begin{array}{l}\text { Rupture of extensor carpi } \\
\text { radialis brevis. }\end{array}$ \\
\hline Stage 4 & \begin{tabular}{l} 
Secondary \\
\hline even calcification. \\
Special test for the \\
epianosis of lateral
\end{tabular} \\
\hline adjustmentitis include. \\
\hline
\end{tabular}

\section{Special test for the diagnosis of lateral epicondylitis}

\begin{tabular}{|c|c|}
\hline Mill's Test' & $\begin{array}{l}\text { The examiner places one } \\
\text { hand on lateral epicondyle } \\
\text { for stabilization then } 2 \text { nd } \\
\text { mobilizing hand passively } \\
\text { pronates the forearm, flexes } \\
\text { the wrist and then extends } \\
\text { the elbow. If patient feels } \\
\text { pain on lateral epicondyle } \\
\text { that will indicate the test is } \\
\text { positive. }\end{array}$ \\
\hline Cozen'sTest' & $\begin{array}{l}\text { Subject is asked to actively } \\
\text { pronate the forearm, make } \\
\text { the fist, laterally deviate } \\
\text { and extend the wrist, while } \\
\text { therapist resists the } \\
\text { movement. A sudden sharp } \\
\text { pain in the lateral } \\
\text { epicondyle indicates that } \\
\text { the test is positive. }\end{array}$ \\
\hline Maudsley'sTest & $\begin{array}{l}\text { Radiological studies to } \\
\text { identify this problem may } \\
\text { be complex as the elbow } \\
\text { radiographic studies } \\
\text { (x-ray) are generally } \\
\text { negative. } 25 \% \text { - } 50 \% \text { of the } \\
\text { cases show ectopic } \\
\text { calcification on the lateral } \\
\text { epicondyle, but the } \\
\text { existence doesn't prove to } \\
\text { correct the prospects. } \\
\text { X- Ray can be found to } \\
\text { eliminate chances of the } \\
\text { arthritic changes at the } \\
\text { radiohumeral articulation } \\
\text { or tumor within the } \\
\text { supinator muscle } 1 . \\
\text { Management possibility of } \\
\text { Tennis elbow consist of } \\
\text { corticosteroid, therapeutic } \\
\text { ultrasound, acupuncture, } \\
\text { phonophoresis, laser, } \\
\text { extracorporeal shockwave } \\
\text { therapy, electromagnetic } \\
\text { field therapy, deep friction } \\
\text { massage, cervical } \\
\text { mobilization, taping, elbow } \\
\text { joint mobilization, workout } \\
\text { elbow cuff, and surgery4. }\end{array}$ \\
\hline
\end{tabular}




\section{Mobilization with Movement (MWM)}

Brian Mulligan has freshly described manual therapy involvement in which therapist applied a passive mobilization to a joint and sustained it with simultaneous physiologic (osteokinematic) movement of the joint, which was actively performed by the patient, and passively performed by the therapist ${ }^{10,11}$. The technique termed as "mobilization with movement" (MWM) is claimed to carry about rapid ache relieving effects and activities (like enhanced grip strength) immediately following their function ${ }^{12}$. It had been found that MWM triggers reduced soreness, improves pain free grip strength (PFGS), and increases chance to bear resisted isometric wrist extension, moreover, 2 weeks of the treatment and 1 month follow up revealed full activity and the patients were free from the ache ${ }^{13,14}$.

For this purpose, the physiotherapist applied lateral glide on lateral side while patient flexed and extended the elbow. Even researches ${ }^{10,11,15,16}$ have outlined that the reduced ache as well as enhanced proper grip strength soon after MWM is a cure for lateral epicondylitis.

\section{Manipulation}

Manipulation ${ }^{17}$ assumed substantive good results dealing with lateral epicondylitis, applying deep transverse friction massage (DTFM) in conjunction with Mill's manipulation. Patient needs to follow the procedure 3 times every week for twenty eight days ${ }^{17,18}$.

\section{Deep Transverse Friction Massage (DTFM)}

DTFM is really a precise form of connective tissue massage used specifically towards soft tissue structures, for instance; tendon. It had been developed within an experimental way by manipulation and now utilized widely within rehabilitation practice 10,19-22. Starting position of individual is sitting down with elbow $90^{\circ}$ flexion and forearm supinated. The therapist's thumb is flexed $90^{\circ}$, placed lateral to the lateral epicondyle. DTFM should be given in front of epicondyle; therefore the individual brings his or her thumb onto anterior facet of the bone. The right location can be attained while just a smaller selection of movement is achieved (an interpretation of movements in the medial direction) and once the movement is prevented using a more challenging end-feel. Additional fingers work as fulcrum at the medial side of elbow. The actual active phase in the deep friction is interpretation of movement at the front end of the particular lateral epicondyle, together with force employed is medial/downward route. DTFM is usually applied 10 minutes each day or at least after 48 hours due to painful hyperemia caused, to arrange the particular tendon for tricks 17,18,19,21,23. Unfortunately, this technique has evolved as very agonizing although patient shouldn't abduct the arm, nor thumb of therapist ought to be set way too high or far too flat. The physical therapist's hand and patient's skin move in a single model, if not necessarily subcutaneous fascia might lead to blister formation or bruising ${ }^{19}$ stimulates vasodilatation along with increased blood flow to areas. This could reduce irritants and improve the transportation associated with endogenous opiates, resulting in diminished pain throughout.

\section{Mill's Manipulation}

Mill's manipulation is the commonest technique used by physiotherapists ${ }^{19,20,24}$. It is convinced that manipulation should be performed directly following DTFM so long as the patient features a complete choice of elbow extension passively. If this passive elbow extension is unchangeable, thrust in manipulation probably influences the elbow articulation, more readily large velocity steady thrust ${ }^{17,18}$.

The position of patient is sitting and therapist stands at the back, the person holds the affected arm of patient in $90^{\circ}$ abduction using internal rotation in order that the olecranon is pointed upward. The therapist flexes the wrist; pronates the forearm with one hand while other hand is placed on olecranon process. Although keeping the wrist in flexion and pronation the physiotherapist delivers low amplitude, high velocity thrust by the end range of elbow extension.

This kind of exercise is usually accompanied only at every therapy session because it is not at all a relaxed technique to sufferer, and the issue of therapy frequently turns into fully apparent within the following week 17,18,24.

\section{METHODOLOGY}

\section{Study setting}

Study was conducted in Physiotherapy OPD in Ziauddin Hospital (Clifton, North and Kemari campuses) and also in Ziauddin college of Physical Therapy.

\section{Study design}

Randomized Control Trial

\section{Duration of the study}

Six month

Sampling technique

Simple Random Sampling.

\section{Sample size}

A sample of 20 patients was included in the study. Sample size calculated through open Epi calculator.

Group A: MWM + Exercise

Group B: Manipulation + Exercise

Inclusion criteria

i. Unilateral symptomatic lateral epicondylitis.

ii. Both female and males between 20 to 50 years of age, suffering from tennis elbow from last 1 to 5 month

iii. Tenderness and pain over the origin of extensor muscle of forearm.

iv. Pain in one of the following special test: Cozen 
test, Mill's test and Maudslay's test.

\section{Exclusion criteria}

i. History of previous surgeries or fracture at the elbow joint.

ii. If complete extension cannot occur at elbow.

iii. Hyper mobile joint.

iv. Hypersensitive skin.

v. Use of steroid injection during last 3 months.

vi. Osteoporosis

\section{Data Collection Tool}

- Patient - Rated Forearm Evaluation Questionnaire.

- Hand held dynamometer - Baseline evaluation instrument.

\section{Main Outcome Method}

The outcome measures are:

- Pain (visual analog scale)

- Hand grip (hand held dynamometer)

- Patient rated tennis elbow evaluation questionnaire (functional status)

\section{Intervention}

Subjects were randomly assigned into 2 groups.

\section{Group A}

10 patients received MWM. Patients were instructed to lie supine with elbow extended and forearm supinated on the treatment table. The therapist stabilized distal part of humerus, mobilizing hand at the proximal radius to apply lateral glides from lateral border of $2^{\text {nd }}$ metacarpal then the patient was instructed to move elbow in extension and flexion. MWM was applied with sustained pressure of lateral glide up to thirty seconds. It was done for three sets with thirty seconds rest time at every alternate day (3 times a week) for 4 weeks.

\section{Group B}

10 patients received Manipulation. DTFM and mills manipulations were applied on Lateral Epicondyle at every alternate day (3 times a week) for 4 weeks.

\section{Deep Transverse Frictions Massage (DTFM)}

The patient sits with elbow in $90^{\circ}$ flexion and forearm supination. The examiner's thumb is in $90^{\circ}$ flexion, with the pad of the thumb lateral to the lateral epicondylitis. The DTF has to be applied at the anterior of the LE with force applied in a medial/downward direction. DTF can be requested 10 minutes so that desensitizing effects occur to arrange this tendon for mills manipulation.

\section{Mills Manipulation}

Mill's manipulation executed instantly after the DTF. Patient is in sitting position with backrest; therapist stands posterior to the patient. The arm of patient is in $90^{\circ}$ abduction, internal rotation and forearm pronation. The therapist hold the patient's wrist in full flexion, the other hand is placed over the olecranon although maintaining the full flexion of the wrist and pronation of the forearm, the therapist gives thrust at the end range of extension of the elbow joint.

\section{Data analysis procedure}

Statistical package for social science (SPSS - 20) was used to evaluate data, standard deviation and means.

\section{RESULT}

The purpose of this study was to compare the effect of Mobilization with movement (MWM) with exercises Vs Manipulation (DTFM and Mill's manipulation) to minimize pain and improving the grip strength and functional status of the involved extremity as a result of Lateral Epicondylitis.

A total of 20 patients were randomly

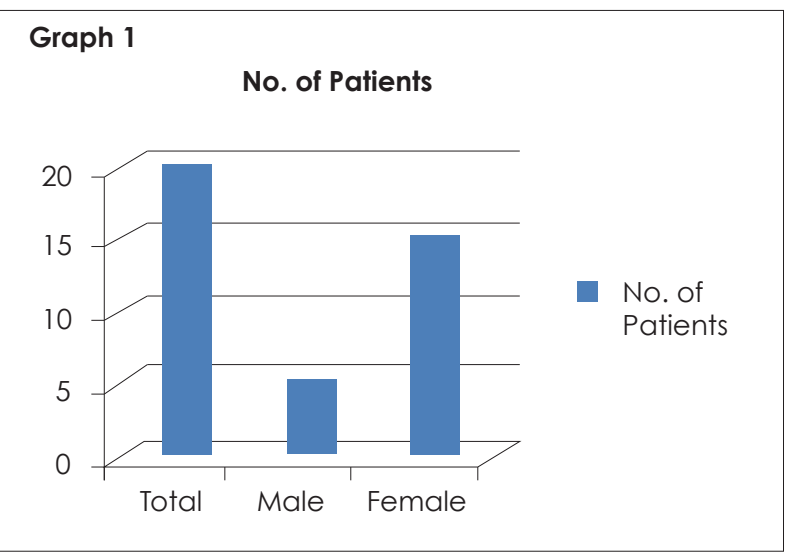

selected and divided in to 2 equal groups including 5 males and 15 female patientsas shown in graph 1 .

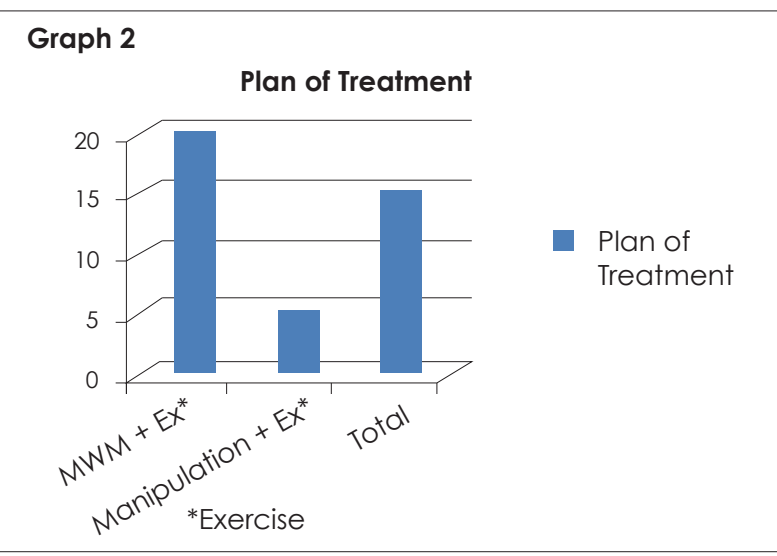

In this study group A received treatment including MMW with exercises and group B received Manipulation with exercises as shown in the below graph 2. VAS

\section{Group A}

The result shows that the mean pain score of VAS before treatment $4.70 \pm 1.418$, but after treatment VAS were decreased and intensity of pain was 0.10 \pm 0.316 . $P$ - Value $<0.05$.

\section{Group B}

It has been observed that mean pain score of VAS before treatment was $5.20 \pm 0.632$ and after treatment it was decreased and new value $0.5 \pm 0.527$. $P$ - Value < 0.05

Table 1 showed that the improvement in both pre and post VAS in group A and group B with both treatment methods were same. 


\begin{tabular}{|c|c|c|c|}
\hline \multicolumn{4}{|l|}{ Table 1} \\
\hline & \multicolumn{2}{|c|}{ Mean \pm SD } & P-Value \\
\hline \multirow[t]{2}{*}{ Group A } & Before & $\begin{array}{l}4.70 \pm \\
1.418\end{array}$ & \multirow{2}{*}{$<0.05$} \\
\hline & After & $\begin{array}{l}0.10 \pm \\
0.316\end{array}$ & \\
\hline \multirow[t]{2}{*}{ Group B } & Before & $\begin{array}{l}5.20 \pm \\
0.632\end{array}$ & \multirow{2}{*}{$<0.05$} \\
\hline & After & $\begin{array}{l}0.5 \pm \\
0.527\end{array}$ & \\
\hline
\end{tabular}

\section{Grip Strength}

It has been observed that the mean of grip strength in Group A before treatment was $13.40 \pm 7.442$ and after treatment the score was $22.60 \pm 8.501$. The result of group $B$ showed that the mean of Grip strength before the treatment was $26.20 \pm 21.028$ and after treatments score was $32.00 \pm 24.33$. Result mentioned in table 2.

Table 2 shown that there was significant improvement in grip strength in post treatment of both groups with both treatment methods, but there is no significant difference in treatment methods

\begin{tabular}{|l|l|l|l|}
\hline \multicolumn{3}{|c|}{ Table 2 } & \multicolumn{2}{|c|}{ Mean \pm SD } & P- Value \\
\hline \multirow{2}{*}{ Group A } & Before & $13.40 \pm$ & \\
& & 7.442 & \multirow{2}{*}{$<0.96$} \\
\cline { 2 - 3 } & After & $22.60 \pm$ & \\
\hline \multirow{2}{*}{ Group B } & Before & 26.501 & \\
& & 21.028 & \multirow{2}{*}{$<0.27$} \\
& After & $32.00 \pm$ & \\
& & 24.33 & \\
\hline
\end{tabular}

\section{DISCUSSION}

In this study we compared the effectiveness of mobilization with movement (MWM) with exercises and Manipulation with exercises to reduce the pain, improve grip strength and improved functional activity in lateral epicondylitis. After fulfilling the inclusion criteria, 20 subjects were assigned in 2 groups i.e. 10 Subjects in group A received mobilization with movement (MWM) with exercises at every alternate days (3 days a week) for 4 weeks. 10 subjects in group $B$ received Manipulation with exercises at every alternate day (3 days a week) for 4 weeks.

Gender wise distributions of groups are randomly assigned in 5 males and 15 females to avoid the biasness.

After 4 weeks of treatment group A and group B were compared through assessment tools, VAS and hand grip dynamometer as an outcome measure for pain and pain free grip power in LE patients.

In this study, we observed that after treatment both groups have significant improvement in pain on VAS, whenever both treatment methods had similar results. On other hand there is also increased in grip strength in group $A$ and $B$, but there was no significant difference in both treatment methods.

In this study the age groups were mostly found between the 20 to 50 years. Dimberg ${ }^{23}$ concluded in his study that the incidences of lateral epicondylitis are increasing with advancing age.

In this study, Manipulation (DTF and Mill's manipulation) was used to treat patients with LE in which this plan of treatment was prescribed for 3 times per week for 4 weeks periods. Results of this study suggested that patient had pain relief and improved hand grip strength which was considered statistically significant. This study supports the results which were obtained in similar studies done by many Authors $24-26$ where Manipulation is used for patients with LE.

Cyriax, Stasinopoulos D, Stasinopoulos I suggested that DTFM treatment plan should encompass 10 minutes almost alternate morning or at least within 48 hrs. DTFM needs to be personalized by good patient's verbal explanation of pain and also good 'objective' examination by therapist regarding selective tissue strain. This kind of advice was just followed in the treatment method, which could actually identify the true purpose for muscles related results to additional scientific tests.

Stasinopoulos D, Johnson M I right after their particular broad study upon Manipulation provides DTFM along with Mill's manipulation would be wise to possibly be given in combo to the affected individual along with LE rather than any method on its own. This particular recommendation through several writers was being powerfully considered in our study exactly where DTFM along with Mill's manipulation was used in combination on affected individual along with LE rather than deciding on individual manual technique ${ }^{26}$.

Stasinopolous D performed a study on exercise program and concluded that stretching exercises and eccentric exercises are effective in the treatment of lateral epicondylitis ${ }^{27}$.

Abbott $\mathrm{JH}^{27}$ did a work which includes 45 subjects with LE which concluded that MWM is a promising intervention modality pertaining to dealing with affected individuals with LE, allowing $92 \%$ of subjects to achieve in the past painful movement to pain free, as well as improving grasp power promptly later. 
In case report explained by Vicenzo \& Wright ${ }^{28}$, raised in functional activity immediately after mulligan's technique. As in many cases, ache would be the key of which limit the actual functional activity within people along with LE. Simply and efficiently by treating pain, MWM furthermore allows you to strengthen the opportunity to achieve daily functional activity.

Geetu as well as Deepak ${ }^{29}$ confirmed that MWM induced a significant increased in muscle strength.

\section{Recommendation and limitations}

- Absence of a subject during treatment period made it difficult to differentiate between effectiveness of treatment caused problem in internal validity of study.

- Female has less strong grip strength than male affecting the grip strength result.

- The study should be repeated as a single blind or double blind to decrease the bias.

- Hand held dynamometer must be comfortable, if it is causing hurt result may be effect.

- In study same etiology should be used because it can affect the study outcome.

- Each group gotten numerous treatment; therefore it is difficult to notice that which part of treatment method acquired the greatest effect on result.

\section{CONCLUSION}

In this study, we were used 2 treatment methods on the parameters of pain in VAS and grip strength using hand held dynamometer respectively, it were showed that reduced in pain and increased in grip power by given MWM \& Manipulation with exercises in group $A$ \& $B$, there were significant improvement in both groups after treatment. Hence, there was no significant difference in the effects of both treatment methods.

\section{Ethical Consideration}

The results have been kept secret. Agreement was drawn by the ethical review committee along with prepared permission from the patient and the purpose of the research was explained before conducting the research.

\section{REFERENCES}

[1] Vincenzino B, broolsbank J, Minto J, Offord S, Paungmali A. Initial affects of elbow taping on pain-free grip strength and pressure pain threshold. J Orthop Sports Phys Ther. 2003;33:400-407

[2] Cyriax J. Book of Orthopaedic Medicine. AICBS publication Delhi. 2000;1 1 (1)

[3] Kushner S, Reid DC. Manipulation in the treatment of tennis elbow. J Orthop Sports Phys Ther. 1986;7:264-272

[4] Wood WA, Starwart A. Lateral epicondylalgia an overview. J Phys ther. 2006;1 1:155-160
[5] Stasinopoulos D, Johnson MI. Cyriax physiotherapy for tennis elbow/lateral epicondylitis. $\mathrm{Br} \mathrm{J}$ Sports Med. 2004;38:675-677

[6] Ciccotti MC, Schwartz MA, Ciccotti MG. Diagnosis and treatment of medial epicondylitis of the elbow. Clin Sports Med. 2004;23:693-705

[7] Stoeckart R, Vleeming A, Snijders Cl. Anatomy of the extensor carpi radialisbrevis muscle related to tennis elbow. Clin Biomech. 1987;4:10-12

[8] Verhaar J. Tennis elbow: anatomical, epidemiological and therapeutic aspects. Int orthop 1994; 18:263-267

[9] Magee DJ. Orthopedic physical assessment. 6th ed. Canada: Saunders Elsevier; 2014

[10] Noteboom T, Cruver S, Keller A et al. Tennis elbow. A review. J Orthop Sports Phys Ther 1994;19:357-66

[11] Chang R W, Dunlop D, Gibbs J, Hughes S. The determents of walking velocity in the elderly. Arthritis Rheum. 1995;38:343-350

[12] Bursch S. Interrater reliability of diastasis recti abdominis measurement. Phys Ther. 1987;67(7):1077-1079

[13] Clapp JF. A clinical approach to exercise during pregnancy. Clin Sports Med. 1994;13(2):443-458

[14] O'Sullivan SB, Schmitz TJ. Physical rehabilitation: assessment and treatment. Jay pee brothers: new Delhi. 2001;5:316,825,937

[15] Stratford P, Levy D, Gowland C. Evaluative properties of measures used to assess patients with lateral epicondylitis at the elbow. Physiother. 1993;45:160-164

$\mathrm{Ng}$ GYF, Fan ACC. Does elbow position affect

[16] strength and reproducibility of power grip measurements? Physiother. 2001;87(2):68-72

Cyriax HJ, Cyriax JP. Cyriax's illustrated manual

[17] of orthopaedic medicine. Oxford ButterworthHeinemann; 1983

Kesson M, Atkins E. Orthopaedic medicine: a

[18] practical approach. Oxford Butterworth-Heinemann; 1998

Selvier T, Wilson J. Methods utilized in treating

[19] lateral epicondylitis. Phys Ther Rev. 2000;5:117-1124

Wright A, Sluka K. Non pharmacological treat-

[20] ments for musculoskeletal pain. Clin J Pain 2001;17:33-46

Chamberlain G. Cyriax's friction massage. A

[21] review. J Orthop Sports Phys Ther. 1982;4:16-22

De Bruijn R. Deep transverse friction its analgesic

[22] effect. Int J Sports Med. 1984;5:35-6

Gregory M, Deane M, Mars M. Ultrastructural

[23] changes in untraumatised rabbit skeletal muscle treated with deep transverse friction. Physiother. 2003;89:408-416

Kushner S, Reid D. Manipulation in the treatment

[24] of tennis elbow. J Orthop Sports Phys Ther. 1986;7:264-272

Dimberg $L$. The prevalence and causation of

[25] tennis elbow (lateral humeral epicodylitis) in a population of worker in an engineering industry. Ergonomics. 1987;30(3):573- 579 
Stasinopoulos D, Johnson MI. Cyriax physiother-

[26] apy for tennis elbow/lateral epicondylitis. $\mathrm{Br} \mathrm{J}$ Sports Med. 2004:38:675-677

Stasinopoulos D, Stasinopoulos K, Johnson MI.

[27] An exercise progamme for management of lateral elbow tendinopathy. $\mathrm{Br} J$ sports med. 2005;39:944-947

Vicenzino B, Wright A. Effects of a novel manip-
[28] ulative physiotherapy technique on tennis elbow: a single case study. Man Ther A. 1995; 1:30-35

Geetu M, Deepak G. Effectiveness of move-

[29] ment with mobilization compared with manipulation of wrist in case of lateral epicondyilitis. Indian J Physiother Occup Ther. 2008;2 